\title{
Management of ST-elevation myocardial infarction in the setting of anterior epistaxis: focused on antiplatelet and antithrombotic therapies
}

This article was published in the following Dove Medical Press journal International Medical Case Reports Journal

\author{
Victoria Handoyo' \\ Gusti Ayu Riska Pertiwi' \\ I Putu Yuda Prabawa ${ }^{2,3}$ \\ Ida Bagus Amertha Putra \\ Manuaba ${ }^{4,5}$ \\ Agha Bhargah ${ }^{6}$ \\ I Putu Gede Budianal \\ 'Department of Cardiovascular \\ Medicine, Mangusada Regional \\ Hospital, Badung, Bali, Indonesia; \\ ${ }^{2}$ Master Program in Biomedicine, \\ Faculty of Medicine, Udayana \\ University, Bali, Indonesia; \\ ${ }^{3}$ Department of Clinical Pathology, \\ Faculty of Medicine, Udayana \\ University, Sanglah General Hospital, \\ Bali, Indonesia; ${ }^{4}$ International Program \\ of Medicine, Taipei Medical University, \\ Taipei, Taiwan; ${ }^{5}$ Medical and Health \\ Education, Faculty of Medicine, \\ Udayana University, Bali, Indonesia; \\ ${ }^{6}$ Faculty of Medicine, Udayana \\ University, Bali, Indonesia
}

Correspondence: Victoria Handoyo Department of Cardiovascular Medicine, Mangusada Regional Hospital, Raya Kapal Street, Mengwi, Kapal, Badung, Bali 8035I, Indonesia

Tel +62878603। I I II

Email victoria_handoyo@yahoo.com
Background: Antiplatelet and antithrombotic therapies are part of standard core treatments for ST-elevation myocardial infarction (STEMI). Effectiveness of these therapies, however, is often offset by the resultant hemorrhagic complications, which in turn possess significantly worse prognosis. Acute myocardial infarction (AMI) accompanied by acute bleeding, such as anterior epistaxis, is common and arise potential dilemma in deciding appropriate management as a standard medical strategy that may put patients in immediate threat as it increases the ongoing bleeding event.

Case description: A 46-year-old male patient with late-onset infero-posterolateral STEMI and anterior epistaxis was admitted to the emergency ward of Mangusada Regional Hospital. The patient had long-standing history of uncontrolled hypertension and previously been treated with tranexamic acid to stop nasal bleeding. Neither percutaneous coronary intervention nor fibrinolysis was performed due to financial issue, and patient only managed conservatively with adequate medications including dual antiplatelet with aspirin and clopidogrel and anticoagulant with unfractionated heparin. No active bleeding was observed during in-hospital treatment and the patient was then discharged after 8 days with complete improvement of symptoms and STsegment elevation resolution.

Conclusion: This case report highlights the treatment strategy for patients with myocardial infarction in the setting of acute bleeding focusing on antiplatelet and anticoagulant therapies. We also discussed the potential association between tranexamic acid and arterial thromboembolic complication resulting in AMI.

Keywords: anterior epistaxis, antiplatelet, antithrombotic, STEMI, conservative management

\section{Introduction}

Managing ST-elevation myocardial infarction (STEMI) in patient with acute bleeding can be very challenging. These two problems have contradiction therapy; acute coronary syndrome (ACS) is caused by thromboembolic event that needs anticoagulant and antiplatelet that can exacerbate bleeding, ${ }^{1}$ whereas acute bleeding needs procoagulant treatment that can exacerbate thromboembolic event. Careful drug selection and correct administration time can be very helpful in managing this case.

Tranexamic acid (TXA) is one of the antifibrinolytic agents, which works by blocking lysine-binding site at plasminogen, thus inhibiting fibrin degradation. TXA is widely used to minimize postoperative bleeding in high-risk surgeries and for chronic bleeding 
disorders. Despite proven effective and well tolerated, several case studies showed an association between TXA and acute myocardial infarction (AMI). ${ }^{2}$

This case outlines specific management therapy focused on antiplatelet and anticoagulant in the setting of STEMI with anterior epistaxis and possible involvement of TXA in precipitating myocardial infarction (MI).

\section{Case presentation}

A 46-year-old male patient presented to the emergency department with acute, dull chest pain in the middle of the chest radiated to the back, accompanied by cold sweating, lasting for $>12$ hours. He also presented with acute profuse nasal bleeding from the right nasal cavity on admission.
Previously, patient had three episodes of recurrent nasal bleeding a few hours before the onset of chest pain and was prescribed $1 \mathrm{~g}$ of TXA twice daily. Patient had several risk factors for coronary artery disease (CAD) including longstanding uncontrolled hypertension since 10 years ago treated with amlodipine $10 \mathrm{mg}$, and smoking cigarettes one pack/day, though this had been stopped for 5 years until now. Physical examinations were normal, except for hypotension (blood pressure 90/60 $\mathrm{mmHg}$ ) and active bleeding at right anterior nasal septum. ECG showed ST-segment elevation at leads II, III, aVF, V5, V6, and V7-V9 (Figure 1) followed by sufficient increase in cardiac markers $(\mathrm{CK}-\mathrm{MB}=30.93 \mathrm{ng} / \mathrm{mL}$; high-sensitivity troponin $\mathrm{I}=2,113.1 \mathrm{ng} / \mathrm{mL})$. Hemoglobin was slightly decreased to the level of $12.7 \mathrm{~g} / \mathrm{dL}$ (hematocrit
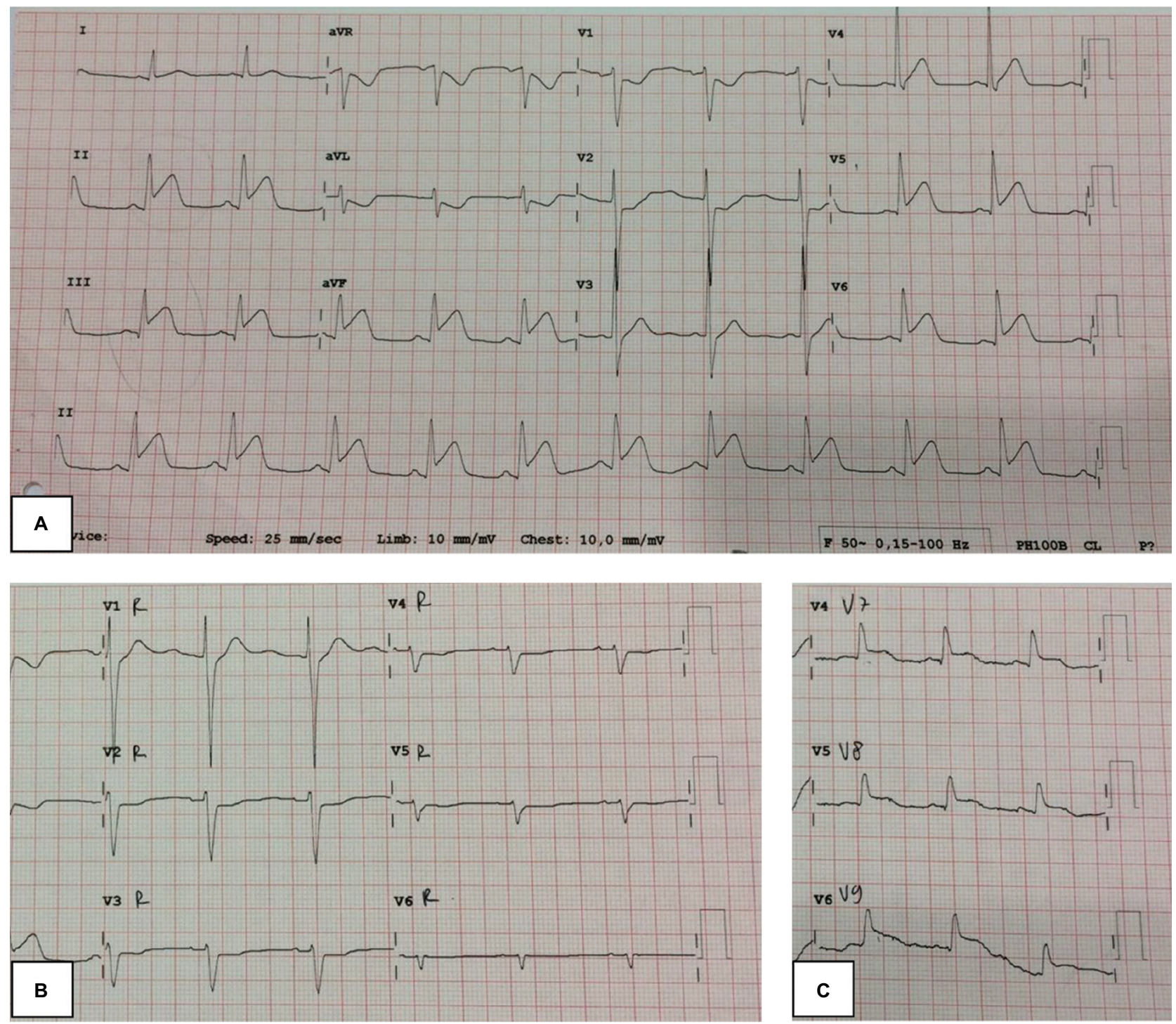

Figure I Electrocardiogram readings at emergency department.

Note: (A) Standard electrocardiogram; (B) right electrocardiogram; (C) posterior electrocardiogram. 
$39.2 \%)$, with normal platelet count $\left(296 \times 10^{3} / \mu \mathrm{L}\right)$ and hypokalemia ( $2.9 \mathrm{mmol} / \mathrm{L})$. Prothrombin time and activated partial thromboplastin time (aPTT) were 10.4 and 23 seconds, respectively. Complete blood count (CBC) examination is shown in Table 1.

A loading dose of normal saline solution $500 \mathrm{cc}$, intravenous morphine injection $2.5 \mathrm{mg}$, isoborbide dinitrate 5 $\mathrm{mg}$, and simvastatin $20 \mathrm{mg}$ were given as part of STEMI management. For anterior epistaxis, an anterior nasal tampon with gentamycin was placed to stop nasal bleeding along with prophylaxis oral amoxicillin 500 thrice/day. Invasive reperfusion could not be performed, as patients refused to do percutaneous coronary intervention (PCI) due to financial issues. Considering comorbid acute bleeding disorder, late-

Table I CBC test at the time of arrival on emergency ward

\begin{tabular}{|l|l|}
\hline Parameters & Values \\
\hline Hematology & \\
WBC & $12.3 \times 10^{3} / \mu \mathrm{L}$ \\
$\quad$ \#Neu & $6.82 \times 10^{3} / \mu \mathrm{L}$ \\
$\quad$ \#Lym & $4.58 \times 10^{3} / \mu \mathrm{L}$ \\
$\quad$ \#Mono & $0.674 \times 10^{3} / \mu \mathrm{L}$ \\
$\quad$ \#Eos & $0.076 \times 10^{3} / \mu \mathrm{L}$ \\
$\quad$ \#Baso & $0.124 \times 10^{3} / \mu \mathrm{L}$ \\
RBC & $4.61 \times 10^{6} / \mu \mathrm{L}$ \\
Hb & $12.7 \mathrm{~g} / \mathrm{dL}$ \\
HCT & $39.2 \%$ \\
MCV & $85 \mathrm{fL}$ \\
MCH & $27.5 \mathrm{pg}$ \\
MCHC & $32.4 \mathrm{~g} / \mathrm{dL}$ \\
RDW & $12.3 \%$ \\
Platelet & $296 \times 10^{3} / \mu \mathrm{L}$ \\
MPV & $4.69 \mathrm{fL}$ \\
Electrolyte (mmol/L) & \\
Na ${ }^{+}$ & 139 \\
K & 2.9 \\
Cl- & 108 \\
Kidney function (mg/dL) & \\
Ureum & 28 \\
Creatinin & 1.2 \\
Uric acid & 5.2 \\
Liver function (U/L) & \\
SGOT & 25 \\
SGPT & 15 \\
Lipid profile (mg/dL) & \\
Total cholesterol & 122 \\
HDL & 30 \\
LDL & 78 \\
Triglyceride & 75 \\
\hline
\end{tabular}

Abbreviations: $\mathrm{CBC}$, complete blood count; Hb, hemoglobin; HCT, hematocrit; $\mathrm{HDL}$, high-density lipoproteins; LDL, low-density lipoproteins; $\mathrm{MCH}$, mean corpuscular hemoglobin; MCHC, mean corpuscular hemoglobin concentration; MCV, mean corpuscular volume; MPV, mean platelet volume; RBC, red blood cells; RDW, red cell distribution width; SGOT, serum glutamic oxaloacetic transaminase; SGPT, serum glutamic pyruvic transaminase; WBC, white blood cells. onset STEMI (>12 hours), and hypotension, thrombolytic therapy was not given. Anticoagulant and antiplatelet were postponed until active bleeding subsided. For the treatment of hypokalemia, $25 \mathrm{mEq}$ potassium chloride in 500 $\mathrm{mL}$ normal saline solution was delivered in 24 hours as intravenous infusion along with oral potassium phosphate thrice/day. After 24 hours of potassium treatment, potassium measurement showed normal value of $3.8 \mathrm{mmol} / \mathrm{L}$, so that intravenous potassium administration was stopped, though blood potassium levels continued to be monitored every 24 hours. Multiple potassium measurements during hospital stay showed potassium levels still within normal limit.

On the following day, the patient's blood pressure increased to $160 / 100 \mathrm{mmHg}$, but no profuse active bleeding was observed. Instead, chest pain was subsided. Amlodipine $5 \mathrm{mg}$, bisoprolol $2.5 \mathrm{mg}$, ramipril $5 \mathrm{mg}$ once daily, laxative lubricant, and a loading dose of unfractionated heparin (UFH) $60 \mathrm{IU} / \mathrm{kilograms}$ of body weight (kgBW) continued with maintenance dose $12 \mathrm{IU} / \mathrm{kgBW} /$ hour were then added to the regimens. Target aPTT was set at 54-90 seconds (1.5-2.5 times of upper normal value). Reevaluation of aPTT at 3,6 , 12 , and 24 hours showed aPTT values 68.2, 64.6, 58.2, and 48.3 , respectively, so that UFH dose was adjusted by increasing $100 \mathrm{IU} /$ hour. After dose adjustment, aPTT continued to be monitored every 6 hours, which was 71.4, 65.3, 55.7, and 51 , respectively, and then UFH was stopped after 48 hours of administration. There was no increase in nasal bleeding during the period of UFH administration. Clopidogrel $75 \mathrm{mg}$ once daily was started on the second day of UFH administration and added by aspirin $80 \mathrm{mg}$ once daily on the next day. Reevaluation of peripheral CBC test was performed after UFH has been stopped to ascertain possible heparin-induced thrombocytopenia (HIT) complication and found platelet level of $304 \times 10^{3} / \mu \mathrm{L}$. However, hemoglobin level decreased to $9.9 \mathrm{~g} / \mathrm{dL}$ (Table 2). Additionally, some bleeding points were still observed on the right nasal cavity examination. Hence, a new nasal tampon was inserted and removed just prior to discharge.

During hospitalization, patient was stable with complete symptoms and ST-segment elevation resolutions as noted on ECG (Figure 2). Patient was discharged at day 7 and arranged for further follow-up at outpatient setting management.

\section{Discussion}

ACS is a spectrum of clinical presentations caused by reduced blood flow in the coronary artery that includes STEMI, nonSTEMI, and unstable angina. It is associated with rupture of an atherosclerotic plaque that can lead to partial or complete 
thrombosis of the infarct-related artery. Thrombosis process was initialized by the dissolution of the fibrous cap of atherosclerotic plaque, then followed by platelet activation and aggregation, activation of the coagulation pathway, and exaggerated by vasoconstriction. In which these events may lead to coronary thrombosis with various degrees of vascular occlusion and may cause distal emboli. ${ }^{3}$

According to ACS pathogenesis, antiplatelet and anticoagulant are essential in managing STEMI. Their use in

Table 2 CBC test following UFH administration

\begin{tabular}{|l|l|}
\hline Parameters & Values \\
\hline Hematology & \\
WBC & $8.51 \times 10^{3} / \mu \mathrm{L}$ \\
\#Neu & $4.24 \times 10^{3} / \mu \mathrm{L}$ \\
\#Lym & $3.09 \times 10^{3} / \mu \mathrm{L}$ \\
\#Mono & $0.88 \times 10^{3} / \mu \mathrm{L}$ \\
\#Eos & $0.28 \times 10^{3} / \mu \mathrm{L}$ \\
\#Baso & $0.02 \times 10^{3} / \mu \mathrm{L}$ \\
RBC & $3.49 \times 10^{6} / \mu \mathrm{L}$ \\
Hb & $9.9 \mathrm{~g} / \mathrm{dL}^{-}$ \\
HCT & $29.3 \%$ \\
MCV & $84 \mathrm{fL}$ \\
MCH & $28.4 \mathrm{pg}$ \\
MCHC & $33.8 \mathrm{~g} / \mathrm{dL}$ \\
RDW & $13.9 \%$ \\
Platelet & $304 \times 10^{3} / \mu \mathrm{L}$ \\
MPV & $9.3 \mathrm{fL}$ \\
\hline
\end{tabular}

Abbreviations: CBC, complete blood count; Hb, hemoglobin; HCT, hematocrit; $\mathrm{MCH}$, mean corpuscular hemoglobin; $\mathrm{MCHC}$, mean corpuscular hemoglobin concentration; MCV, mean corpuscular volume; MPV, mean platelet volume; RBC, red blood cells; RDW, red cell distribution width; UFH, unfractionated heparin; WBC, white blood cells.
ACS therapy is proven effective to improve outcome and minimize adverse events. However, their resultant bleeding risks sometimes outweigh the benefits. Major bleedings were found in 1\%-9\% ACS patients treated with early antithrombotic medications, and a clear relationship between those two were observed. ${ }^{1}$ Patients with major organ bleeding following ACS had 60\% higher risk for in-hospital death and almost five-fold increase in 30-day mortality rates than those without bleeding. ${ }^{4,5}$ Conditions such as older patient aged $>75$ years, female, low body weight, anemia, hypertension, diabetes mellitus, kidney disease, and sepsis are accompanying factors favorable for adverse bleeding events. ${ }^{1,6}$

To date, no guideline or consensus precisely guides about antiplatelet and anticoagulant uses for STEMI patient in the setting of acute nonmajor organ bleeding. ESC guideline strongly recommends patients who come with the clinical presentation of STEMI within 12 hours of initial symptom presentation and with persistent ST-segment elevation or new or presumed new left bundle branch block to undergo early invasive (PCI) or pharmacological reperfusion (fibrinolysis). In patients with clinical presentation beyond 12 hours, PCI should be considered if there is any clinical or electrocardiographic evidence of ongoing ischemia, as the exact onset of symptoms based on patients' information is often unclear or when the pain and ECG changes have been stuttering. ${ }^{7}$

PCI is highly recommended as a reperfusion strategy for STEMI patients with significant bleeding risk. Dual antiplatelet therapy (DAPT) using aspirin and ADP receptor

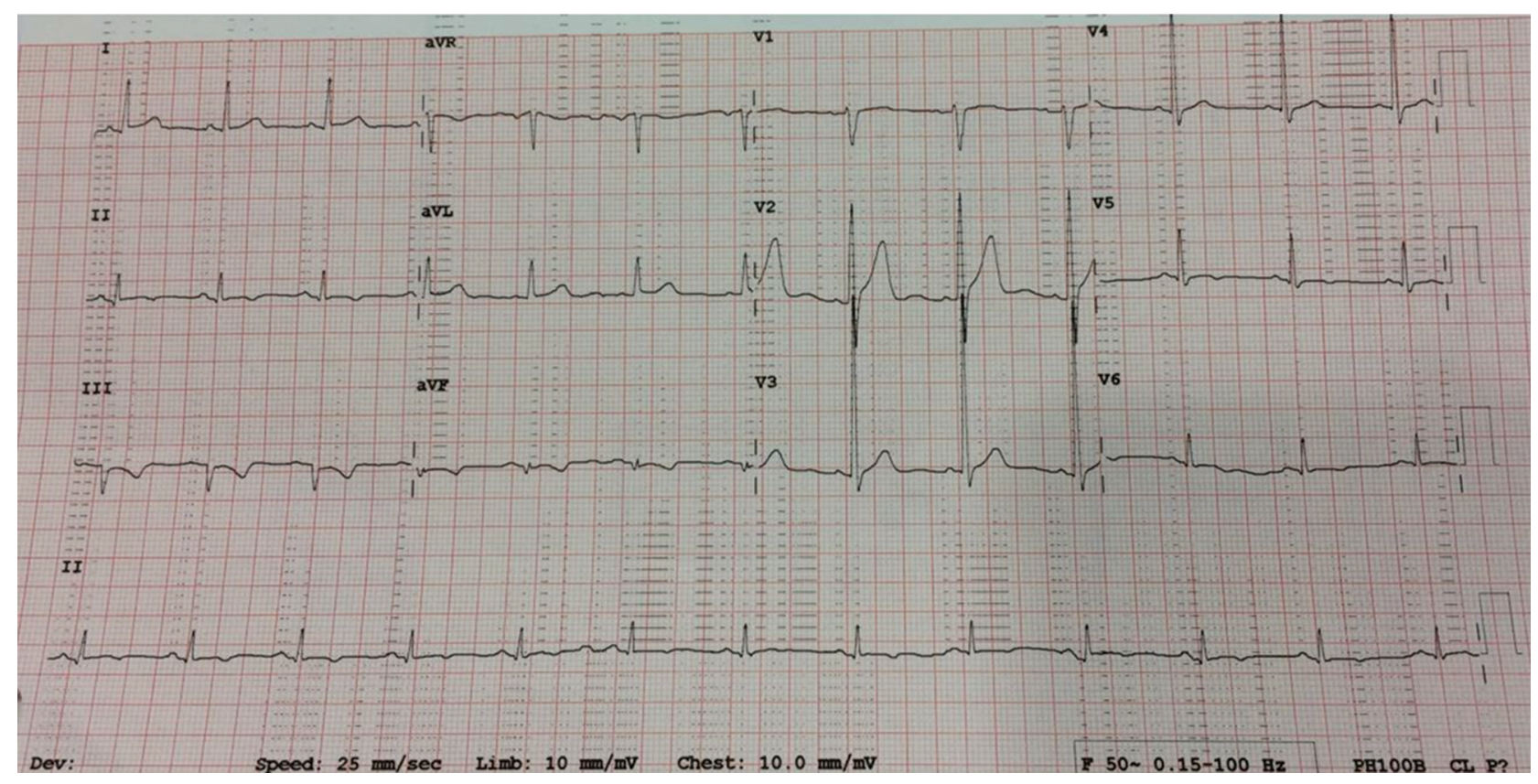

Figure 2 Electrocardiogram on the day of patient discharge. 
blocker should be administered as early as possible before angiography and a parenteral anticoagulant. A lower loading dose for DAPT should be considered in the setting of acute bleeding or high bleeding risk patients. ${ }^{6,7}$ Selection of vascular route and type of stent being used should also consider the patient's preexisting bleeding risk. In this case, no PCI was performed due to patient's financial issue. Given the fact that the efficacy of fibrinolysis and time of symptoms onset to fibrinolysis have a negative linear association, it was also not done in the current case. Although acute anterior epistaxis is not explicitly stated as a contraindication for fibrinolysis, we considered it comparable with the criteria of known bleeding disorder (excluding menses) criteria in lists absolute contraindication to fibrinolysis. ${ }^{7,15}$

In this case, patient came with STEMI accompanied by active nasal bleeding. Aspirin, clopidogrel, and heparin agent were not given at initial presentation due to the possibility of increasing ongoing nasal bleeding. After the bleeding had been reduced, UFH was chosen as the first antithrombotic drug management because of the short plasma half-life of UFH. Bleeding from the adverse effect of UFH administration can often be managed by stopping this drug. Moreover, only UFH has an antidote that can rapidly be administered when severe bleeding event encounters. ${ }^{6,8}$ Protamine sulfate can be used to quickly reverse the effect of UFH if adverse effects occur. This substance can form a stable salt with heparin leading to its inactivation. ${ }^{8}$

Because UFH and low-molecular weight heparin (LMWH) have rapid onset of antithrombotic activity, they are considered as the main choice of anticoagulants in the setting of acute thrombosis. Heparin is considered as an indirect anticoagulant for its action is depended on the presence of antithrombin (AT) ${ }^{8-10}$ Those two regiments are widely used in STEMI patients with PCI, but LMWH is not superior to UFH in the context of reducing adverse bleeding risk. ${ }^{6}$ Fondaparinux is a synthetic pentasaccharide that has ability to bind selectively and irreversibly to AT, which results in inactivation of factor $\mathrm{Xa}$, thus inhibiting thrombin formation and thrombus development. Unlike LMWH and fondaparinux that are administered as a subcutaneous injection, UFH is administered as continuous intravenous infusion so that it can be stopped anytime if adverse effect occurs. UFH also has shorter half-life compared with LMWH and fondaparinux. The drawback of fondaparinux in managing adverse effect is that it does not respond to protamine sulfate. ${ }^{8-10}$ Its parenteral way administration is also preferable over several enteral drugs like aspirin and clopidogrel as it is easier and controllable. ${ }^{11}$ The most significant issues concerning UFH therapy is the bleeding effect and HIT. Major bleeding accounts for $0 \%-7 \%$, whereas fatal bleeding accounts for $0 \%-3 \%$ of the total patients who were given UFH therapy. HIT happened in about $1 \%-5 \%$ of patients. CBC should be checked after UFH administration to ascertain there is no HIT. ${ }^{10}$

Clopidogrel can reduce the combined risk of ischemic stroke, MI, or vascular death in patients with cardiovascular disease slightly better than aspirin. Clopidogrel is also significantly better than aspirin in preventing recurrent cardiovascular events in patient who have had an MI or stroke, according the Clopidogrel vs Aspirin in Patients at Risk of Ischemic Events trial. It showed fewer side effects, including gastrointestinal bleeding than aspirin. ${ }^{12,13}$ In the CURE (The Clopidogrel in Unstable Angina to Prevent Recurrent Events) trial, a secondary analysis showed that higher aspirin dose $(320 \mathrm{mg})$ has higher correlation to bleeding event compared with combination of aspirin $(70 \mathrm{mg})$ and clopidogrel $(100 \mathrm{mg}) .{ }^{1,11}$ Both drugs inhibit platelet aggregation for the life span of the platelet. Its effect last longer and cannot be reversed. ${ }^{13}$ In our case, clopidogrel was given first in addition to UFH on the second day of UFH administration since it is safer than aspirin. And then aspirin was added to the regimen after UFH was stopped.

Another interesting issue that can be further discussed in this report is the possible effect of TXA in precipitation of AMI. As depicted above, the patient consumed $1 \mathrm{~g}$ of TXA prior to the onset of chest pain to stop his epistaxis. Until recently, there are only few case reports presenting the patient with AMI with a history of TXA consumption either for preexisting bleeding disorder or as prevention after highrisk procedures. ${ }^{2}$ Most of the patients in these reports already had known CAD risk factors such as hypertension, obesity, smoker or tobacco use, and prior MI (in our case, patient had uncontrolled hypertension and previous smoking habit). ${ }^{2}$ However, there was only one case study that observed AMI in a very low risk 41-year-old female patient who was taking TXA for menorrhagia. Her coronary angiography revealed $70 \%$ at posterior and midsegment of first diagonal branch of left anterior descending coronary artery suggesting underlying CAD before TXA treatment. ${ }^{14}$ However, considering ACS pathogenesis that involves a series of platelet aggregation and coagulation pathway activation, possible TXA effect on precipitating the onset of MI cannot be fully excluded.

\section{Conclusion}

The main choice in handling patients with STEMI is to use primary PCI but in special case such as STEMI accompanied by active nasal bleeding, UFH can be an alternative choice since it has a rapid onset of antithrombotic activity, short 
half-life, administered as a continuous intravenous infusion and can be rapidly reversed with protamine sulfate. Administration of DAPT is encouraged, though close monitoring to adverse bleeding events is mandatory.

\section{Ethical consideration}

The patient was given information regarding the publication of the case report and signed an informed consent prior to any data collection. Current case report has been approved by the Ethical Committee of Mangusada General Hospital, Badung, Bali, Indonesia, with reference number 048/RSUDM.02.1.2/ $\mathrm{PD} / \mathrm{KEP} / 2018$. Institutional approval is not needed for publication of detailed case reports.

\section{Disclosure}

The authors report no conflicts of interest in this work.

\section{References}

1. Fitchett D. The impact of bleeding in patients with acute coronary syndromes: how to optimize the benefits of treatment and minimize the risk. Can J Cardiol. 2007;23(8):663-671.

2. Calapai G. Systematic review of tranexamic acid adverse reactions. $J$ Pharmacovigil. 2015;03(04):1-7.

3. Abbate R, Cioni G, Ricci I, Miranda M, Gori AM. Thrombosis and acute coronary syndrome. Thromb Res. 2012;129(3):235-240.

4. Moscucci M, Fox KA, Cannon CP, et al. Predictors of major bleeding in acute coronary syndromes: the global Registry of acute coronary events (GRACE). Eur Heart J. 2003;24(20):1815-1823.

5. Eikelboom JW, Mehta SR, Anand SS, Xie C, Fox KA, Yusuf S. Adverse impact of bleeding on prognosis in patients with acute coronary syndromes. Circulation. 2006;114(8):774-782.
6. Victor SM, Mullasari A. Complex STEMI management: treatment of STEMI in patients with bleeding risk. E Jour Cardiol P. 2016;14(29):1-6.

7. Ibanez B, James S, Agewall S, et al; ESC Scientific Document Group. 2017 ESC guidelines for the management of acute myocardial infarction in patients presenting with ST-segment elevation: the Task Force for the Management of Acute Myocardial Infarction in Patients Presenting with ST-Segment Elevation of the European Society of Cardiology (ESC). Eur Heart J. 2018;39(2):119-177.

8. Makris M, Van Veen JJ, Tait CR, Mumford AD, Laffan M, British Committee for Standards in Haematology. Guideline on the management of bleeding in patients on antithrombotic agents. Br J Haematol. 2013; 160(1):35-46.

9. Leonard SL. Pathophysiology of Heart Disease. 6th ed. Boston: Lippincott Williams \& Wilkins; 2008.

10. Obermeyer Z, Lee TH, Ziad O, Thomas HL. Lost in thought - the limits of the human mind and the future of medicine. $N$ Engl J Med. 2017;377(13):1209-1211.

11. Roffi M, Patrono C, Collet JP, Marco L, Carlo PJP. 2015 ESC guidelines for the management of acute coronary syndromes in patients presenting without persistent ST-segment elevation: Task Force for the Management of Acute Coronary Syndromes in Patients Presenting without Persistent ST-Segment Elevation of the European Society of Cardiology (ESC). Eur Heart J. 2016;37(3):267-315.

12. McQuaid KR, Laine L. Systematic review and meta-analysis of adverse events of low-dose aspirin and clopidogrel in randomized controlled trials. Am J Med. 2006;119(8):624-638.

13. Moshfegh K, Redondo M, Julmy F, et al. Antiplatelet effects of clopidogrel compared with aspirin after myocardial infarction: enhanced inhibitory effects of combination therapy. J Am Coll Cardiol. 2000;36(3):699-705.

14. Ngo-Thai LL, Gellatly R, Nanayakkara S. Tranexamic acid precipitating onset of acute myocardial infarction. J Pharm Pract Res. 2015;45(1):46.

15. Ganatra S, Sharma A, Levy MS. Re-evaluating the safety of drugeluting stents in cancer patients. JACC Cardiovasc Interv. 2017;10(22): 2334-2337.
International Medical Case Reports Journal

\section{Publish your work in this journal}

The International Medical Case Reports Journal is an international, peer-reviewed open-access journal publishing original case reports from all medical specialties. Previously unpublished medical posters are also accepted relating to any area of clinical or preclinical science. Submissions should not normally exceed 2,000 words or

\section{Dovepress}

4 published pages including figures, diagrams and references. The manuscript management system is completely online and includes a very quick and fair peer-review system, which is all easy to use. Visit $\mathrm{http}: / /$ www.dovepress.com/testimonials.php to read real quotes from published authors. 